\title{
Lig op Satan en Satanisme vanuit die Nuwe Testament 1
}

\author{
Fika J. van Rensburg \\ Departement Klassieke en Semitistiek \\ PUCHO/Teologiese Skool \\ POTCHEFSTROOM
}

\section{INLEIDING}

\subsection{Algemene inleiding}

In hierdie artikel word, in aansluiting by en as voorsetting van prof. Vosloo se "Lig op Satanisme vanuit die Ou Testament" ook in die Nuwe Testament lig op die Satan en Satanisme-verskynsel gesoek. Wat die aard van die inhoud van hierdie artikel betref, probeer ek doelbewus om die stof só aan te bied dat dit gemaklik tot die gemiddelde ernstige Bybelleser kommunikeer. Derhalwe is die aanpak nie akademies-wetenskaplik nie, maar populêr-wetenskaplik.

\subsection{Die Bybel se manier van praat oor die bonatuurlike}

\subsubsection{Metaforiese taal}

Voordat die gegewens in die Nuwe Testament met betrekking tot Satanisme aan die orde kom, is dit belangrik om aandag te gee aan die wyse waarop daar in die Bybel oor die bonatuurlike gepraat word. God openbaar Homself en sy manier van werk in die Bybel noodwendig deur middel van taal. Hierdie 'openbaring' beteken dat daar op 'n menslike wyse (naamlik deur middel van die betrokke alledaagse taal) onder andere oor die bonatuurlike, dit is die sake wat vir ons menslike sintuie nie-waarneembaar is, gehandel word. Die mens moet praat oor iets wat vir hom nie net onbekend is nie, maar ook onwaarneembaar.

Om dit te kan regkry, word die metaforiese funksie van taal ingespan, dit wil sê: oor onbekende nie-waarneembare dinge word in terme van bekende waarneembare dinge gepraat. Beelde uit die alledaagse werklikheid word gebruik om 'n nie-waarneembare werklikheid mee te beskryf. Dit is byvoorbeeld die wyse waarop inligting oor God self en oor sy doen en late in die Bybel beskryf word. Kom ek noem twee voorbeelde:

$1 \quad$ Hicrdic artikel is ' $n$ verwerking van 'n referaal gelewer tydens 'n daglange seminaar oor Satanisme, aangebied deur die Sentrum vir Voortgeseltc Teologiesc Opleiding van die Universiteit van Pretoria. 
- Jesus Christus se getroue versorging en beskerming van die gelowiges word uitgedruk in terme van die werk van 'n 'goeie skaapwagter' (Johannes 10). ${ }^{2}$

- God se liefdevolle versorging word uitgedruk in terme van die rol wat 'n goeie pa in die verhouding met sy kind speel (Matteus 7:11). ${ }^{3}$

Daar word dus noodwendig op 'n antropomorfiese (mensvormige) wyse gepraat. Hierdie metaforiese gebruik van taal moet - veral by die interpretasie van gegewens oor die aard en aktiwiteite van Satan - in gedagte gehou word. Veral moet groot versigtigheid aan die dag gelê word wanneer afleidings gemaak word op grond van die beeldryke taal in die Nuwe Testament.

\subsubsection{Die rol van die destyds reeds-bestaande oortuigings}

Die noodwendige talige kommunikasie oor die bonatuurlike het die verdere implikasie dat die reeds bestaande oortuigings oor (in hierdie geval) die Satan, noodsaaklikerwys 'n rol speel in die wyse waarop die betrokke skrywers van die Nuwe Testament dit wat God in hierdie verband deur hulle aan die mens kommunikeer, onder woorde bring. In hierdie talige kommunikasie word die bestaande woordeskat en denkkategorieë gebruik. In vele opsigte word nuwe inhoud daaraan gegee en die nodige korreksies aangebring. Indien sulke aansluiting nie moontlik was nie, sou inligting oor die bonatuurlike feitlik nie-kommunikeerbaar wees.

\subsection{Die opset van hierdie artikel}

Die oogmerk met hierdie artikel is om Nuwe-Testamentiese gegewens oor die Satan op 'n oorsigtelike wyse aan te bied sodat dit toeganklik en bruikbaar kan wees vir verdere besinning oor die Satanisme. Die bedoeling van die artikel is om, op grond van die inligting oor die Satan, 'n riglyn te gee vir die houding teenoor Satanisme en die hantering van persone wat daarby betrokke is.

Met die oog op hierdie doelwitte kom die volgende sake nou agtereenvolgens aan die orde:

- In die eerste plek kyk ons na die inligting in die Nuwe Testament oor die oorsprong en bestaan van die Satan (2).

2 Vers 11 is 'n goeie voorbeeld: "Ek is die goeie herder. Die goeie herder lê sy lewe af vir die skape:"

3 Matteus 7:9-11: "Watter mens onder julle sal vir sy seun 'n klip gee as hy brood vra, of 'n slang as hy vis vra? As julle wat sleg is, dan weet om vir julle kinders gocie dinge te gee, hoeveel te meer sal julle Vader wat in die hemel is, goeie gawes gee aan dié wat dit van Hom via?* 
- Daarna bepaal ons sekere eienskappe van die Satan op grond van verskeie van sy name en tiperings in die Nuwe Testament (3).

* Vervolgens word onderskei tussen die duiwel (enkelvoud) en duiwels (meervoud), en word daarvoor gepleit dat ons eerder van demone as duiwels moet praat (4).

- Die strategie van die Satan word bespreek, naamlik sy aanslag eers op Jesus Christus en dan op die gelowiges (5).

- Ten slotte word gehandel oor die implikasie van ons verlossing van die mag van die Satan ten opsigte van ons houding teenoor Satanisme en ons hantering van persone wat tot Satanisme neig (6).

\section{DIE OORSPRONG EN BISTAAN VAN DIE SATAN}

Die Nuwe Testament teken Satan as 'n persoon wat werklik bestaan. Oor sy oorsprong is daar - soos wat dit die geval in die Ou Testament is - in die Nuwe Testament groot terughoudendheid. Wat wel duidelik is, is dat hy voorgestel word as 'n geskape engel. Hieruit is af te lei dat hy nie ' $n$ tipe anti-god is wat soos God van ewigheid af bestaan en op gelyke voet met God in stryd is nie. Verder is dit duidelik dat hy nie as 'n slegte wese geskape is nie, maar dat dit 'n toestand is wat met sy val ingetree het.

In Openbaringe 12:3 word die volgende in verband met die Satan gesê:

Daar het ook ' $n$ ander teken in dic hemel verskyn: daar was ' $n$ grest vuurtoosi draak met sewe koppe en tien horings, en op sy koppe was daar sewe heerserskrone. Sy stert het 'n derde van die sterre van dic hemel saamgeslecp en hulle op die aarde gegooi ...

Baie teoloë verklaar hierdie beskrywing asof dit die val van die Satan beskryf en lei ook af dat een derde van die engele saam met hom geval het. Hierdie verklaring het baie probleme. Dit lyk eerder asof Johannes hier bloot die mag en verskriklikheid van die Satan se verskyning beskryf. Enige verdere afleidings is grootliks spekulatief en moet liewer nie gemaak word nie. Die doel met die beskrywing in Openbaringe 12 is nie om die Satan se oorsprong te verduidelik nie, maar wel sy mag en die verskriklikheid van sy aanslag. Oor laasgenoemde kan mens uit hierdie teks met veiligheid afleidings maak, maar nie oor sy ontstaan en oor sy bonatuurlike volgelinge nie. ${ }^{4}$

\section{DIE NAME VAN SATAN 5}

Die bedoeling met hierdie afdeling is nie om te probeer om 'n betekenisdefinisie van elke naam te gee nie, maar om met die verskillende name as invalspoort, sekere fasette

4 Dil is warskynlik na aankiding van dic fouticwe verklaring van Jesaja 14:12-15 dat te veel en ongeldigc afleidings vit Openbaringe 12 gemaak word.

5 Gocic oorsigtclike behandelings hicrvan is te vind in De Bondt (sj:118-156), Coctzec (1987:24-26), en Hicberl (1975:282). Dic Louw-Nida-woordebock (1988) bicd ook waardevolle inligling. 
van die gegewens oor Satan in die Nuwe Testament te ontgin. Daarom word Skrifgedeeltes wat Satan tipeer, aangehaal en kortliks bespreek, met die oog daarop om te bepaal wat ons gesindheid teenoor Satan, die persoon wat sentraal staan in die Satanisme, moet wees.

\subsection{Direkte name}

Die Satan word in die Nuwe Testament met verskeie name aangedui. Twee hiervan, naamlik Satan en Duiwel word as primêre benamings gebruik, en veral Satan funksioneer feitlik as eienaam. Hierdie benamings is ook grootliks uitruilbaar.

Dit is nie geldig om met stelligheid allerhande afleidings oor die persoon van die Satan uit die waarskynlike etimologiese betekenisse van hierdie twee name af te lei nie. Tog is dit interessant om, in die lig van die tipering van die Satan elders in die Nuwe Testament, op die etimologiese betekenis van die twee woorde te let. Die naam Satan 6 tipeer hom as die teëstander of die vyand van God en die aanklaer van die mens by God. Duiwel, ${ }^{7}$ wat in die oorspronklike verband hou met die Afrikaanse woord diabolies, is waarskynlik beskrywend van die Satan se werkwyse: dat hy uitmekaarskeur en verbreek (in die sin van die wig indryf tussen mense en God, en tussen mense onderling), en dat hy 'n revolusionêr is, iemand wat gesag wederregtelik vir homself toeëien, en op grond daarvan net wil maak en breek soos hy goed dink.

\subsection{Karakteriserende beskrywings}

Benewens die bogenoemde 'direkte' name is daar in die Nuwe Testament ook talle 'karakteriserings' van die Satan. Elkeen van hierdie karakteriserings is beskrywend van die een of ander faset van die Satan se aard of sy aktiwiteite. Ons kyk kortliks na 'n paar hiervan.

\subsubsection{Die groot draak, die slang van ouds}

In Openbaring 12 word die aanslag van die Satan op die vrou beskryf, asook die oorlog waarin Migael en sy engele die Satan en sy engele verslaan. In verse 8-9 staan daar:

In die hemel was daar geen spoor meer van hulle te vind nie, want dic groot draak, ${ }^{8}$ die slang van ouds, ${ }^{9}$ wat die duiwel en die Satan genoem word en wat die hele wêreld verlei, is uit die hemel

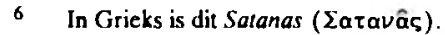

7 Die Griekse woord is diabolos ( $\delta$ ı́ $\beta \circ \lambda \circ \varsigma)$.

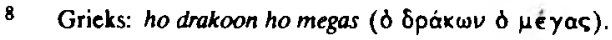

9 Grieks: ho ofis ho archaios (o $6 \phi 15$ d̀ apxaîos).
} 
uit gegooi. Hy is op die aarde gegooi en sy engele saam met hom.

Met hierdie beeld word die Satan as monster, as verskriklike wese geteken, en sy aktiwiteit as wêreldverleier word aangedui.

\subsubsection{Die aanklaer van die medegelowiges}

In die direk opvolgende vers in Openbaring (12:10) staan die volgende woorde: "Die aanklaer ${ }^{10}$ van ons medegelowiges is uit die hemel uit gegooi." Hieruit blyk dit dat die Satan sy aankla-funksie verloor het.

\subsubsection{Beělsebul, die aanvoerder van die demone}

Nadat Jesus 'n man wat blind en stom was, genees het, het "die Fariseërs hiervan gehoor en gesê: 'Hy dryf duiwels uit alleen met die hulp van Beëlsebul, die aanvoerder van die demone"'11 (Matteus 12:24). Daar is dus algemeen aanvaar dat die Satan die hoof van die demone is. Verder laat die aanhaling blyk dat 'n tipiese naam vir die Satan in hierdie tyd Bë̈lsebul was.

\subsubsection{Belial, die vors van die duisternis}

In 2 Korintiërs 6:14-15 staan daar: "Hoe kan daar gemeenskap wees tussen lig en duisternis? Hoe kan daar eenstemmigheid wees tussen Christus en Belial?" In die Nuwe Testament word die naam Belial net hierdie een keer gebruik. In ander literatuur wat in die tydperk van die ontstaan van die Nuwe Testament in omloop was, naamlik die Joodse apokaliptiese literatuur, is Belial (of: Beliar) egter die algemene naam vir die Satan, die hoof van die demone.

\subsubsection{Die Bose}

In die gelykenis van die onkruid tussen die koring vertel Jesus dat die vyand van die saaier in die nag onkruid tussen die koring gesaai het. In Jesus se verklaring van die gelykenis sê Hy onder andere: "Die onkruid is die aanhangers van die Bose;"12 die vyand wat die onkruid saai, is die duiwel." Hier word die duiwel dus die Bose genoem. Die gelykenis beeld verder uit dat die aanhangers van die duiwel die gelowiges kortwiek soos wat onkruid koring kortwiek. Die onkruid tipeer "almal wat ander mense in sonde laat val. en almal wat die wet van God oortree" (Matteus 13:41). Die uiteinde van hierdie aanhangers van die duiwel is dat hulle in terme van die gelykenis "in die brandende oond gegooi" word waar hulle "sal huil en op hulle tande kners"

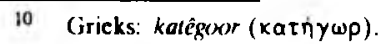

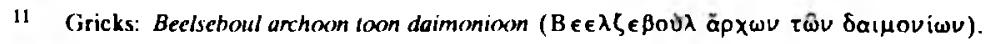

12 (iricks: ponêros (rounpós).
} 
(Matteus 13:42).

\subsubsection{Die god/owerste van hierdie wêreld}

Paulus skryf in 2 Korintiërs 4 oor die evangelie wat hy verkondig, en dat "die evangelie ... bedek is net vir dié wat verlore gaan. Hulle is die ongelowiges wie se verstand deur die god van hierdie wêreld ${ }^{13}$ verblind is, sodat hulle die lig van die evangelie nie kan sien nie" (2 Korintiërs 4:3-4). Hierdie tipering kom grootliks ooreen met dié in Johannes 12:31: "Nou kom die oordeel oor hierdie wêreld, nou sal die owerste van hierdie wêreld ${ }^{14}$ uitgegooi word buitentoe."

Albei hierdie tiperings dui daarop dat die Satan mag het, maar dat daar duidelike perke aan verbonde is. Hierdie mag as (af-)god en (revolusionêre) owerste het hy natuurlik nie regtens nie; hy het dit wederregtelik vir homself toegeëien. Verder laat die term owerste blyk dat Satan net 'n owerste, dit wil sê 'n ondergeskikte maghebber is, terwyl God as Koning die Satan onder sy beheer het.

\subsubsection{Die vors van die onsigbare bose magte}

Die skrywer van Efesiërs skryf in hoofstuk 2 se eerste verse oor sy lesers se lewe voor hulle bekering. In vers 2 sè hy: "Julle het . . julle laat lei deur die vors van die onsighare bose magte, 15 die gees wat daar nou aan die werk is in die mense wat aan God ongehoorsaam is." Hierdie tipering skyn sinoniem te wees met Beëlsebul, die aanvoerder van dic demone in Matteus 12:24.

Uit ander Skrifdele blyk dit dat die Satan oor die demone (Lukas 11:18), die gevalle mensdom en "hierdie wêreld" (Johannes 12:31), die gevalle engele, die dood en die doderyk (Hebreërs 2:14) regeer. By baie bestaan die verkeerde opvatting dat die hel ook deel van die Satan se regeerjurisdiksie is. Dit is egter nie die geval nie. Die hel is die 'plek' wat vir die Satan berei is, sy ewige 'plek' van verdoemenis, waar God hom na die finale oordeel gaan plaas.

\subsubsection{Verleier}

In 1 Tessalonisense 3:5 word die Satan as verieier getipeer: "Ek het vir Timoteus gestuur om vas te stel... of die verleier ${ }^{16}$ julle nie reeds verlei het en al ons harde werk

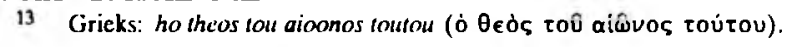

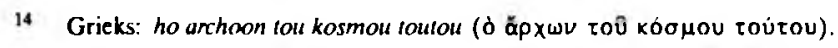

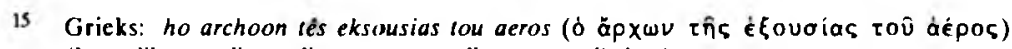
(Letterlike vertaling: "dic owerste van dic mag van die lug").

16 Grieks: ho peirazoon (ò $\pi \in \operatorname{lpá\zeta \omega \nu ).~}$
} 
dalk op niks uitgeloop het nie." Hiermee word die Satan ooreenkomstig een van sy wesensaktiwiteite getipeer.

3.2.9 Vader van die ongelowiges, moordenaar, leuenaar en vader van die leuen

In Johannes 8 van vers 31 af is Jesus besig om vir Jode wat nie in hom glo nie, te sê dat hulle nie God as Vader het nie. In vers 44 staan daar dan:

Julle is kinders van die duiwel; hy is julle vader, ${ }^{17} \mathrm{en} \mathrm{julle} \mathrm{wil} \mathrm{doen} \mathrm{wat} \mathrm{julle} \mathrm{vader} \mathrm{wil} \mathrm{hê} \mathrm{julle}$ moel doen. Hy was van die begin af 'n moordenaar. ${ }^{18}$ En hy staan nie aan dic kant van dic waarheid nic, omdat daar geen waarheid in hom is nie. Wanneer hy leventaal praat, is dit volgens sy aard, want hy is 'n leuenaar ${ }^{19}$ en dic' vader van die leuen.

Al drie hierdie tiperings laat wesensaktiwiteite van die Satan blyk:

* Soos 'n vader 'versorg' hy die mense wat in sy diens staan.

* Hy is nie net die een wat die mens (Kain) tot die eerste moord aangespoor het nie, maar ook die oorsprong van alle moord en doodslag.

* Leuentaal is een van sy besondere aktiwiteite.

\subsection{Samevatting}

Die een saak wat voorlopig uit hierdie behandeling duidelik blyk, is dat Satan nie 'n tipe anti-god is, sodat daar twee gode, 'n goeie en 'n slegte is nie. Satan is 'n geskape wese, 'n revolusionêre selfaangestelde regeerder wat deur God toegelaat word en in die volvoering van sy raadsplan gebruik word.

\section{DEMONE, EN DIE VERHOUDING; TUSSEN SATAN EN DIE DEMONE}

Albei ons huidige Afrikaanse vertalings handhaaf nie die onderskeid wat daar in die oorspronklike tussen duiwel en demone is nie. Die Griekse woord vir demoon, naamlik daimonion ( $\delta \alpha \iota \mu o ́ v ı o v)$, word net soos diabolos ( $\delta\llcorner\alpha \beta \circ \lambda \circ \varsigma$ ) met duiwel weergegee. In Markus 1:34 staan daar byvoorbeeld:

Jesus het baic sickes wat allerhande kwale gehad hel, gesond gemaak en baie diawels 20 vitgedrywe. Hy het die duiwels nie toegelaat om te praat nie, omdat hulle geweet het wic $\mathrm{Hy}$ is.

Die probleem met hierdie vertaling is dat dit nie blyk dat daar net een duiwel en baie demone is nie. Die Griekse woord diabolos ( $\delta\llcorner\alpha \beta o \lambda o \zeta)$ verwys na die persoon, die Duiwel, die geestelike engelewese met die eienaam Satan, die owerste van hierdie

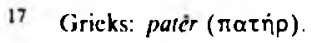

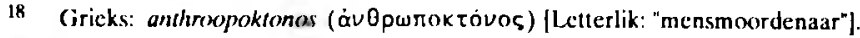

19 Gicks: pseustès ( $\psi \in$ úotns).

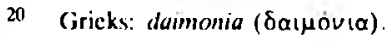


wêreld. Die ander woord, daimonion ( $\delta \alpha$ เóv vov) verwys weer na die volgelingmagte van die Satan in die geesteswêreld naamlik die gevalle engele wat in y diens staan. Hulle word ook bose/onrein geeste ${ }^{21}$ en met enkele ander benaminge genoem.

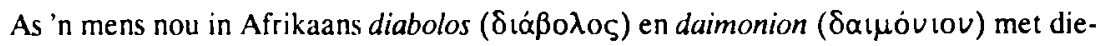
selfde woord duiwel weergee, skep dit verwarring. ${ }^{22}$ Myns insiens is die woord demoon en sy byvoeglike naamwoord demonies bekend genoeg in Afrikaans om as 'n weergawe van die Griekse woord gebruik te word. As dit uit 'n Afrikaanse oogpunt onaanvaarbaar sou wees, moet die Griekse woordgroep ten minste met iets soos bose gees(te) vertaal word.

Die gedeelte in Markus 1:34 sal soos volg lees as ons demone in plaas van duiwels gebruik:

Jesus het baie siekes wat allerhande kwale gehad het, gesond gemaak en baic dimone uitgedrywe. Hy het dic demone nie toegelaat om te praal nic, omdat hulle geweet het wic $\mathrm{Hy}$ is.

Insgelyks moet die werkwoorde en byvoeglike naamwoorde wat aan daimonion ( $\delta \alpha \iota \mu$ oviov) verwant is, ${ }^{23}$ dienooreenkomstig in Afrikaans weergegee word:

- Die werkwoord sal dan nie meer wees in die mag van 'n duiwel nie, maar in die mag van ' $n$ demoon.

- Die byvoeglike naamwoord sal dan nie meer duiwels wees nie, maar demonies. ${ }^{24}$

Hierdie onderskeid behoort belangrike implikasies te hê wanneer daar oor besetenheid gehandel word.

21 Byvoorheeld Lukas 7:21: 'Op daardie oomblik hel Jesus juis haic mense gesond gemaak van sicktes en kwale en bose geeste, en baie blindes het Hy laal sien."

22 Reeds in die Nederlandse Statevertaling is hierdie fouticwe vertaling gemaak, cn albei ons Afrikaanse vertalings het dit opgevolg. Die King James Version en dic Authorized Version vertaal $\delta \alpha \iota \mu v$ io $\nu$ deurgaans met devils. Enkele nuwe vertalings het egter reeds in 'n ander rigting begin bewecg. So byvoorbecld vertaal die Nederlandse Bybel met dic Bijbel in de

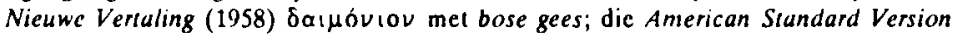
(1929/1973), dic NIV (1973) en dic TIV (1966) vertaal met demon(s).

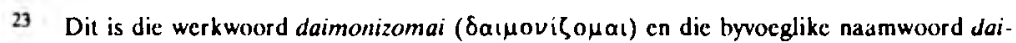

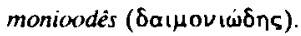

24. Ek het verneem dat die Eindredaksie vir die hersiening van dic 1983-Afrikaansc Vertaling tans besig is om die vertaling van die $\delta a t \mu o ́ v i o v$-woordgrocp te hersien, en dic motivering vir die hersiening kom grootliks ooreen met dit wat ek hier genoem het. Dit kan wees dat nuwe oplae van hierdie Vertaling reeds die veranderings bevat. 


\section{DIE STRATEGIE VAN SATAN}

\subsection{Die aanslag van Satan op Jesus Christus}

Die Satan het aanvanklik sy aanslag op Christus gefokus, soos dit ook in Openbaringe 12 beskryf word. Dink maar aan die persoonlike botsing tussen Jesus en die Satan met die versoekings in die woestyn (Matteus 4:1-11, en parallelle plekke). Die Satan het ook deur middel van demoonbesetenes 'n aanslag op Christus gemaak. Die besetene van Gerasa (Markus 5:1-20) is hiervan 'n goeie voorbeeld. Satan se aanslag op Christus het sy hoogtepunt aan die kruis bereik. Dáár is die stryd egter ook beslis; dáár het Christus nie net die dood oorwin nie, maar ook vir Satan.

\subsection{Die aanslag van Satan op die gelowiges}

Nadat Satan die stryd teen Christus verloor het, rig hy sy aanslag op die geiowiges. In Efesiërs 6:11 word die gelowiges opgeroep om die volle wapenrusting van God aan te trek teen die listige aanslae van die duiwel, en in 2 Korintiërs 2:10-11 word die gelowiges gewaarsku teen die komplotte van Satan. Dit blyk dat Satan gebruik maak van direkte blatante aanvalle, soos byvoorbeeld vervolging. Daar is egter ook individuele besoekings: die merendeel individuele versoekings is egter listige aanslae, aanslae waarin die skrikwekkende draak in 'n skelm slang verander. Hy maak gebruik van verleidings van buite, soos die leuen, valse leer, ondermyning van ampswerk, en meesleuring in die stroom van die wêreld. Hy maak egter ook gebruik van aanslae van binne die hart uit - versoekings soos geldsug, eersug en selfsug in die algemeen, eienskappe wat tipies is van die natuurlike geaardheid van die onwedergebore mens.

\section{VERLOSSING DEUR CHRISTUS SE OORWINNING OOR SATAN}

\subsection{Jesus Christus se finale oorwinning oor Satan}

Jesus se finale oorwinning oor Satan word besonder duidelik in Hebreërs 2:14-15 beskryf, waar daar staan dat Jesus mens geword het "om deur sy dood dié een wat mag het oor die dood, dit is die duiwel, te vernietig en om hulle wat uit vrees vir die dood hulle hele lewe lank in slawerny was, te bevry".

Ook in 1 Petrus word Jesus se oorwinning in duidelike taal vermeld. Daar staan dat dat Jesus wel as mens doodgemaak is, maar deur die Gees lewend gemaak is (1 Petrus $3: 18$ ). Hy het hierdie oorwinning by die geeste in die gevangenis (waarskynlik die gevalle engele) aangekondig (1 Petrus 3:19), en Hy sit nou as regeerder aan die regterhand van God, "nadat Hy die engele en die magte en die kragte aan Hom onderwerp het!" (1 Petrus 3:22). Daar is dus geen twyfel daaroor dat Jesus finaal oor Satan en sy magte oorwin het nie. 


\subsection{Implikasie van Jesus Christus se oorwinning oor Satan}

Hierdie feit van die oorwinning van Jesus Christus oor die Satan veroorsaak dat ons as gelowiges nie paniekbevange raak wanneer ons aan die Satan dink of oor Satanisme besin nie. Ons besef immers dat ons deur die Vader "uit die mag van die duisternis weggeruk en onder die heerskappy gestel is van sy Seun" (Kolossense 1:13). Ons kry ook die versekering dat God die Satan spoedig onder die gelowiges se voete sal verpletter (Romeine 16:20).

Die Nuwe Testament laat duidelik blyk dat, wanneer ons oor Satanisme besin, ons dit moet doen vanuit die besef dat Satan op grond van Christus se oorwinning 'n verslane vyand is. Dit hou in dat ons ferm standpunt teen die duiwel moet inneem. Ons moet die duiwel teëstaan, en hy sal van ons af wegvlug (Jakobus 4:7). Self kan jy nie van die duiwel af wegvlug nie, maar deur jou te beroep op Christus se oorwinning, laat jy die duiwel op die vlug slaan.

Die aard van die besinning oor Satanisme moet egter nie so wees dat ons inderwaarheid reklame maak vir die Satan nie. Die ondertoon van ons besinning moenie angs en vrees wees nie, maar rustige fermheid, gebaseer op die wete dat Christus die Satan oorwin het, en dat ons as mense wat "deur die Heilige Gees gesalf is en die waarheid ken" (1 Johannes 2:20) in Christus meer as oorwinnaars is!

Van ons Here het ons die opdrag om die duiwel nie 'n vatkans te gee deur aan ons onwedergebore natuurlike geaardheid vrye teuels te gee nie (Efesiërs 4:25-27). Iemand wat toegee aan sy natuurlike geaardheid, moet weet dat sy lewe verwoes sal word (1 Petrus 2:11). Eerder moet ons nugter en wakker wees, bedag op die duiwel wat soos 'n brullende leeu rondloop (1 Petrus 5:8). Die manier waarop dit moet gebeur, is deur die wapenrusting wat God gee, aan te trek:

Trek dic volle wapenrusting aan wat God julle gec, sodal julle op julle pos kan bly ondanks die listige aanslac van die duiwel. Ons stryd is nie teen vlees en bloed nie maar teen dic bose magte van hierdic sondige wêreld, teen die bose geeste in die lug (Efesiërs 6:11-12).

Ons wét immers dat ons die oorwinning oor Satan behaal het "danksy die bloed van die Lam" (Openbaring 12:11).

Dít is die sentrale boodskap wat daar volgens die Nuwe Testament moet uitgaan in ons besinning oor Satanisme. Ons moet Christus se finale oorwinning oor die Satan besef, beleef en beklemtoon, asook die wyse waarop Christus ons in daardie oorwinning laat deel. Mense wat tot die Satanisme aangetrokke voel, se oë moet op hierdie wyse oopgemaak word, "sodat hulle hulle van die duisternis tot die lig en van die mag van die Satan tot God kan bekeer" (Handelinge 26:18). 
Hierdie sentrale boodskap is dus een van oorwinning en goeie nuus, en nie in die eerste plek 'n alarmskreeuery waardeur juis vir die Satanisme 'goedkoop' reklame gemaak word nie. Die boodskap is dus 'n bevrydingsboodskap, en kan in 'n neutedop soos volg saamgevat word:

Satan is nie meer die baas van die dood nie! Jy is dus nie meer slauf van die duiwel nie. Jy staan nie in sy diens nie en jy hoef nie te doen wat hy wil hê nie. Jesus Christus het met sy eie dood en opstanding die Satan ooruin! Sien Jesus met eer en heerlikheid gekroon, en besef en beleef dat $\mathrm{Hy}$ die Satan oorwin het. Vertrou jouself aan Hom toe. Erken net Hom as Baas: luister vir Hom en rig jou lewe in soos wat $H_{y}$ dit wil hê.

\section{TEN SIOTIE}

Die lig op Satanisme vanuit die Nuwe Testament dring ons dus om saam met Paulus dit uit te jubel:

Hicrvan is ek oortuig: geen dood of lewe of engele of bose magte of teenswoordige of toekomstige dinge of kragte of hoogle of diepte of enigiels anders in die skepping kan ons van die liefde van God skei nie, die liefde wat daar is in Christus Jesus ons Here (Romeine 8:38-39).

\section{ENKEIE BRONNE WAT GERAADPI.EEG KAN WORD}

BIETENHARD, H. 1980. Saluóviov. (In Brown, C.ed. The New International Diclionary of the New Testament. Theology Exeter : Pater Noster Press. Vol. 1:4.50.453.)

COETZEE, J.C. 1987. Satan en sy magte in die Nuwe Testament - Besonderlik tecnoor die Heilige Gecs. Skrif en Kerk, 8(1):20-37.

COETZEE, J.C. 1988. Memoranda vir die Eindredaksie vir hersiening van die 1983-Verıaling van dic Suid-Afrikaanse Bybelgenootskap.

DE BONDT, A. s.j.(a) De Satan. Baarn : Bosch \& Keuning NV.

DE BONDT, A. s.j.(b). Daemonische invloeden in ons leven. Den Haag : JN Voorhoeve.

GROVC, A.H. 1989. Die Bose en die Kerk volgens Openbaringe 2 en 3. (Ongepublisecrde MA. verhandeling - Universiteit van die Oranje-Vrystaat.)

HARRISON, R.K. 1975. Demon, Demoniac, Demonology. (In Tenney, M.C. ed. The Zondervan Pictorial Encyclopedia of the Bible. Grand Rapids : Zonderian. Vol. 2:92-101.)

HERING, J 1973. Demons. (In Von Almen, J.J. ed. Vocabulary of the Bible. London : Guildford Press. p. 83-85.)

HIEBERT, D.E. 1975. Satan. (In Tenney, M.C. ed. The Zondervan Pictorial Encyclopedia of the Bible. Grand Rapids : Zondervan. Vol. 5:282-286.)

LOUW. J.P. \& Nida, E.A. 1988. Greck-English Lexicon of the New Testament Based on Semantic Domains. Volumes I \& II Ncw York: United Bible Societies. [Dic inskrywings $\delta$ iaßo

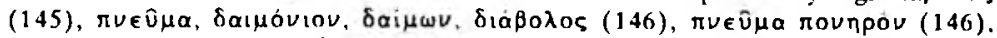

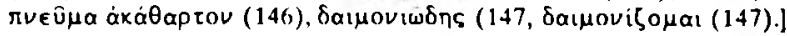


